\title{
Extracellular cGMP in the Hippocampus of Freely Moving Rats as an Index of Nitric Oxide (NO) Synthase Activity
}

\author{
Francesco Vallebuona and Maurizio Raiteri \\ Institute of Pharmacology and Pharmacognosy, University of Genova, 16148 Genova, Italy
}

The nitric oxide (NO) synthase/cGMP pathway has been studied in vivo in the adult rat hippocampus by monitoring the levels of extracellular cGMP during microdialysis in conscious unrestrained animals. The basal cGMP efflux was concentration-dependently reduced upon local infusion of the NO synthase inhibitor $\mathrm{N}^{\mathrm{a}}$-nitro-L-arginine (NARG; $10 \mu \mathrm{M}$ to $1 \mathrm{~mm}$ ). The NO donors hydroxylamine and $\mathrm{S}$-nitroso- $\mathrm{N}$ penicillamine, perfused through the dialysis probe at $1 \mathrm{~mm}$, increased by about $200 \%$ the extracellular levels of cGMP. The glutamate receptor agonist NMDA (125-500 $\mu \mathrm{M})$ produced concentration-dependent cGMP responses that were abolished by the selective receptor antagonist D-2-amino-5phosphonovaleric acid or by NARG. Local perfusion of the phosphodiesterase inhibitor 3-isobutyl-1-methylxanthine (IBMX; $1 \mathrm{~mm}$ ) produced a steady eightfold increase of extracellular cGMP levels. The effect of IBMX was highly sensitive to NARG. The inhibition by NARG of the IBMX-induced CGMP response was reversed when the NO synthase substrate L-arginine was administered. It is concluded that CGMP collected during in vivo microdialysis reflects NO synthase activity in the rat hippocampus. The technique may be utilized to investigate the pathophysiology and the pharmacology of the NO/cGMP pathway in the hippocampus of living animals.

IKey words: nitric oxide synthase, in vivo microdialysis, hippocampus, nitric oxide, cGMP, phosphodiesterase, nitric oxide donors]

Nitric oxide (NO) is being recognized as an important messenger molecule in an increasing number of mammalian tissues (Moncada et al., 1989). NO is formed from the amino acid L-arginine, under the catalysis of NO synthase (Knowles et al., 1989; Bredt and Snyder, 1990). In immunohistochemical studies NO synthase was observed in neurons throughout the brain and the discrete pattern of its localization suggests particular functions for NO as a signaling molecule in synaptic transmission (Garthwaite, 1991; Snyder and Bredt, 1991).

$\mathrm{NO}$ is a potent activator of heme-containing soluble guanylate cyclase and causes cGMP formation in target cells (for reviews, see Waldman and Murad, 1987; Garthwaite, 1991; Snyder and Bredt, 1991). Enhancement of NO production responsible for

Received Mar. 31, 1993; revised June 24, 1993; accepted June 28, 1993.

This work was supported by grants from the Italian MURST and from the Italian CNR. The expert editorial assistance of Mrs. Maura Agate is gratefully acknowledged.

Correspondence should be addressed to Maurizio Raiteri, Istituto di Farmacologia e Farmacognosia, Viale Cembrano 4, 16148 Genova, Italy.

Copyright (C) 1994 Society for Neuroscience 0270-6474/94/140134-06\$05.00/0
cGMP elevation has been described in cerebellar slices of immature and adult rats in response to NMDA receptor activation (Garthwaite et al., 1988; Southam et al., 1991). The NO/cGMP pathway has been described in hippocampal slices of immature rats, and preliminary results suggest that cGMP accumulation linked to NMDA receptor activation also occurs in slices of adult rat hippocampus, although the cGMP response observed was much less pronounced than in slices from the adult cerebellum (East and Garthwaite, 1991).

The hippocampal formation is considered to play a central role in learning and memory processes. Activation of NMDA receptors in this area is essential to the development of longterm potentiation (LTP), a mechanism thought to represent a mnemonic device (see Bliss and Collingridge, 1993). Recent reports suggest that $\mathrm{NO}$ may act as a retrograde messenger in LTP, carrying information from postsynaptic to presynaptic elements (O'Dell et al., 1991; Schuman and Madison, 1991). Similarly, the NMDA receptor $\rightarrow \mathrm{NO} \rightarrow$ cGMP pathway has been implicated in long-term depression (Shibuki and Okada, 1991), a possible cellular mechanism for cerebellar motor learning (Ito, 1989).

A number of pharmacological tools are now available to investigate the $\mathrm{NO} / \mathrm{cGMP}$ pathway, including inhibitors of $\mathrm{NO}$ synthesis, NO scavengers, NO generators, and inhibitors of the cyclic nucleotide phosphodiesterases. The availability of selective drugs and the advancement of in vivo sampling techniques represented by intracerebral microdialysis (Ungerstedt, 1984) might allow study of the NO/CGMP system and its modulations in selected brain areas of the living animal. This work describes the changes of extracellular cGMP caused, in the rat hippocampus subjected to in vivo microdialysis, by administration of drugs expected to affect the NO/cGMP pathway.

\section{Materials and Methods}

Animals. Male Sprague-Dawley rats (CD-COBS, Charles River, Calco, Italy) weighing $250-300 \mathrm{gm}$ were used. They were housed at constant room temperature $\left(22 \pm 1^{\circ} \mathrm{C}\right)$ and relative humidity $(50 \%)$ under a regular light/dark schedule (light 7 A.M. to 7 P.M.). Food and water were freely available.

Dialysis procedure. Rats were anesthetized with $3 \mathrm{ml} / \mathrm{kg}$ Equithesin (pentobarbital, $9.6 \mathrm{gm} /$ liter; chloral hydrate, $42.4 \mathrm{gm} / \mathrm{liter} ; \mathrm{MgSO}_{4}, 21.2$ $\mathrm{gm} / \mathrm{liter}$; propylene glycol, $396 \mathrm{gm} / \mathrm{liter}$; ethanol, $100 \mathrm{gm} / \mathrm{liter}$ ) and placed on a stereotaxic apparatus (David Kopf Instruments). A dialysis probe was transversely positioned in the two dorsal hippocampi of the rat. Stereotaxic coordinates were $\mathrm{AP}=+3.8, \mathrm{H}=+6.5$ from the interaural line according to the Paxinos and Watson atlas (1986). A short piece of dialysis fiber made of a copolymer of acrylonitrile sodium methallyl sulfonate (AN $69 \mathrm{HF}$, Hospal SpA, Bologna, Italy; $0.3 \mathrm{~mm}$ o.d. with more than 40,000 Da cutoff) was covered with epoxy glue to confine dialysis to the area of interest $(8 \mathrm{~mm}$ glue-free zone for the two hippocampi). The rat's skull was exposed and two holes were made on the lateral surface at the level of dorsal hippocampus. One dialysis probe, 
held straight by a tungsten wire inside, was inserted transversely into the brain so that the glue-free zone was exactly located in the target area. The tungsten wire was withdrawn and stainless steel cannulas ( 22 gauge diametcr, about $15 \mathrm{~mm}$ long) were glued to the ends of the fiber. These ends were bent up and fixed vertically to the skull using dental cement and modified Eppendorf tips. Finally, the skin was sutured and the rats were allowed to recover from anesthesia for $24 \mathrm{hr}$ before the beginning of experiment.

On the day of the experiment the rat was placed in a Perspex cage and the probe was perfused with an artificial cerebrospinal fluid (CSF) containing (in $\mathrm{mM}$ ) $145 \mathrm{NaCl}, 3 \mathrm{KCl}, 1.26 \mathrm{CaCl}_{2}, 1 \mathrm{MgCl}_{2}$, in distilled water. The solution was buffered at pH 7.4 with a 2 mM sodium phosphate buffer.

The fibers were perfused at a constant flow rate of $5 \mu \mathrm{l} / \mathrm{min}$ with a CMA/100 microinjection pump (Carnergie Medicin, Stockholm, Sweden), and every $20 \mathrm{~min}$ samples of perfusate were collected in minivials and assayed for their cGMP content. cGMP was determined using a commercially available radioimmunoassay kit ( $\Lambda$ mersham dual range, Amersham Radiochemical Centre, Buckinghamshire, U.K.). The sensitivity of the assay was about $1.0 \mathrm{fmol} / \mathrm{sample}$. The percentage of in vitro recovery for cGMP was $40 \pm 1.2(n=3)$ in our condition of perfusion (flow rate, $5 \mu \mathrm{l} / \mathrm{min} ; 100 \mu \mathrm{l} / \mathrm{sample}$ ). The correct placement of the dialysis probes in the hippocampi was verified by histological examination of fiber tracts.

Statistics and expression of results. The average of the three $20 \mathrm{~min}$ samples collected just before drug treatment was considered as basal value and defined as $100 \%$. The values given are expressed as percentages of basal. Data on Figure 3 are expressed as fmol/100 $\mu 1$ (data not corrected for recovery). The effects between control animals (artificial CSF alone) and treated animals (artificial CSF + drugs) were analyzed by a single two-way ANOVA with repeated measures over time. When significant effects were found, post hoc between comparisons were carried out with Tukey's test.

Materials. L-Arginine, 3-isobutyl-1-methylxanthine (IBMX), and $\mathrm{N}^{\mathrm{G}_{-}}$ nitro-L-arginine (NARG) were of the purest grade available (Sigma Chemical Co., St. Louis, MO). NMDA and D-2-amino-5-phosphonovaleric acid (D-AP5) were purchased from Tocris Neuramin (Bristol, U.K.). $S$-nitroso- $N$-penicillamine (SNAP) was obtained from Cookson Chemicals Ltd. (Southampton, U.K.). Hydroxylamine was obtained from Merck (Darmstadt, Germany). IBMX was dissolved in $\mathrm{NaOH}(0.1$ M) to a concentration of $100 \mathrm{~mm}$; subsequent dilutions were made in artificial CSF. All the other drugs were dissolved in artificial CSF

The experimental procedures in vivo were approved by the Fthical Committee of the Institute of Pharmacology and Pharmacognosy according to the European legislation on the use and care of laboratory animals (CEE 86/605).

\section{Results}

Effects of NO synthase inhibition on basal cGMP efflux. The average basal levels of cGMP in the hippocampal dialysate did not differ significantly between experiments $(18.9 \pm 1.8 \mathrm{fmol} /$ $100 \mu \mathrm{l}$; means $\pm \mathrm{SEM}$ of three consecutive $20 \mathrm{~min}$ samples obtained from 30 animals; data not corrected for in vitro recovery). The basal efflux was stable with time and detectable for at least $140 \mathrm{~min}$. When $\mathrm{Ca}^{2+}$ ions were omitted from the perfusion medium, the basal cGMP outflow was significantly decreased (data not shown).

When the cGMP levels in the dialysates were monitored during infusion with the NO synthase inhibitor NARG, the basal efflux of c(iMP was reduced by the drug $(10 \mu \mathrm{M}$ to $1 \mathrm{mM})$ in a concentration-dependent manner. The maximal inhibitory effect (about $55 \%$ ) was reached $40 \mathrm{~min}$ after infusion of NARG at $1 \mathrm{~mm}$ (Fig. 1).

Effects of NO generators. As shown in Figure $2 A$, hydroxylamine (1 mM) perfused through the probe for $80 \mathrm{~min}$ increased by approximately $200 \%$ the extracellular levels of cGMP. A quantitatively similar increase of the cGMP recovered in the dialysates was produced by infusing for $80 \mathrm{~min} 1 \mathrm{~mm}$ SNAP, another NO donor (Fig. 2B).

Extracellular cGMP following infusion of $N M D A$. The glu-

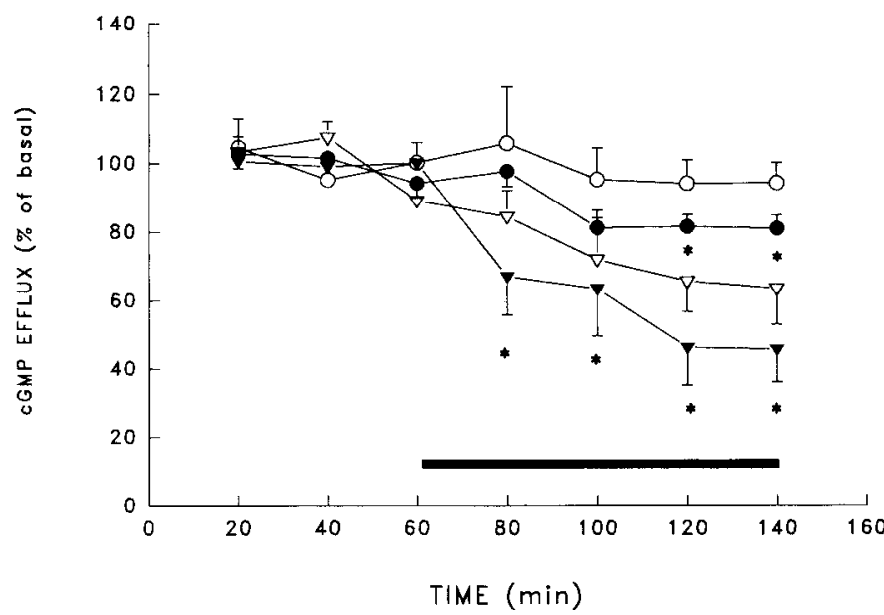

Figure 1. Effects of the NO synthase inhibitor NARG on basal extracellular levels of cGMP in the hippocampus of freely moving rats. Values are expressed as percentage of basal (+SFM; $n=4-6$ for each group). The horizontal bar indicates the time during which different concentrations of NARG were perfused through the dialysis probe. Basal absolute values of cGMP $(34.4 \pm 6.1 \mathrm{fmol} / 100 \mu \mathrm{l})$ did not differ significantly among the four sets of experiments and were grouped together. ${ }^{*}, P<$ 0.01 versus controls and basal samples. For further details, see Materials and Methods. O, controls; $\bullet$, NARG $(10 \mu \mathrm{M}) ; \nabla$, NARG $(100 \mu \mathrm{M}) ; \boldsymbol{\nabla}$, NARG (1 mm).

tamate receptor agonist NMDA $(125-500 \mu \mathrm{M})$, perfused through the dialysis probe for $20 \mathrm{~min}$, produced a dose-related increase in the extracellular concentrations of cGMP (Figs. 3, 4). At the concentration of $500 \mu \mathrm{M}$ the outflow of cGMP reached a maximum at the end of the infusion with NMDA (time $=80 \mathrm{~min}$ in Fig. 3) and rapidly returned to basal in the subsequent fraction. The cGMP levels returned to normal by time $=100 \mathrm{~min}$ also if the NMDA infusion was prolonged up to time $=140$ min (not shown).

As shown in Figure 4, the cGMP response caused by $500 \mu \mathrm{M}$ NMDA was completely abolished when the selective NMDA receptor antagonist D-AP5 $(500 \mu \mathrm{M})$ or the NO synthase inhibitor NARG $(10 \mu \mathrm{M})$ was perfused for $60 \mathrm{~min}$ prior co-infusion with NMDA. D-AP5 $(500 \mu \mathrm{M})$ had no significative influence, on its own, on basal cGMP levels, while NARG $(100 \mu \mathbf{M})$ produced a significant decrease (Fig. 4).

Extracellular cGMP during phosphodiesterase inhibition and effects of NO synthase modulation. When the phosphodiesterase inhibitor IBMX was perfused through the dialysis probe at a concentration of $1 \mathrm{~mm}$, a steady eightfold increase of extracellular cGMP levels was obtained (Fig. 5). The levels of cGMP in the dialysate, in presence of IBMX, were reduced by NARG ( $1 \mu \mathrm{M}$ to $1 \mathrm{mM}$ ) in a concentration-dependent manner (Fig. 6). The maximal effect (about $70 \%$ ) was reached 80 min after infusion of 1 mM NARG. Figure 7 shows that the NO synthase substrate L-arginine ( $1 \mathrm{~mm}$ ) was able to increase by about $40 \%$ the cxtraccllular concentration of cGMP during IBMX perfusion. L-Arginine ( $1 \mathrm{mM}$ ) consistently counteracted the inhibitory action of $100 \mu \mathrm{M}$ NARG on the cGMP response.

Behavioral observations during microdialysis. The perfusion experiments were made the day after surgery to allow the animals to recover and to reduce the effects of anesthesia. In a group of operated but untreated animals, gross behavior and food and water intake appeared normal up to $6 \mathrm{~d}$. No signs of pain or distress were evident throughout the experiments. Dur- 


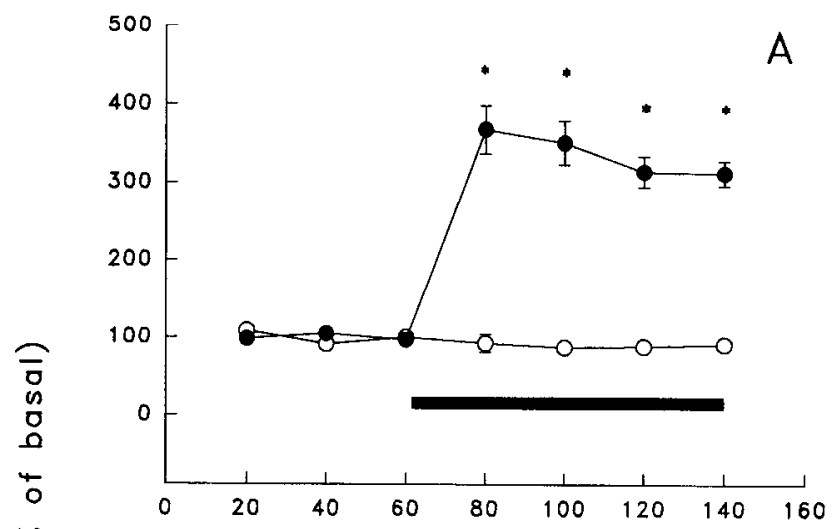

s0

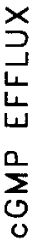

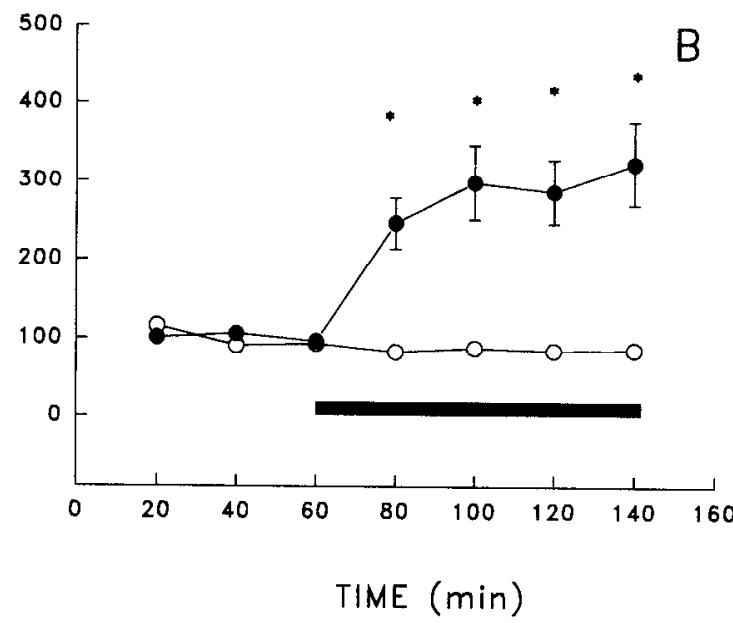

Figure 2. Effects of the NO generators hydroxylamine or SNAP on basal extracellular levels of cGMP in rat hippocampus of freely moving rats. Hydroxylamine or SNAP (1 mM) was perfused through the dialysis probe for $80 \mathrm{~min}$ as indicated by the horizontal bar. For other details, see Materials and Methods. Values are expressed as percentage of basal ( \pm SEM; $n=4-6$ for each group). Basal absolute values of cGMP $(26.8$ $\pm 5.5 \mathrm{fmol} / 100 \mu \mathrm{l})$ did not differ significantly between experiments and were grouped together. $A: \mathrm{O}$, controls; - , hydroxylamine (1 mM). $B: \mathrm{O}$, controls;, SNAP $(1 \mathrm{mM}) .{ }^{*}, P<0.01$ versus controls and basal samples.

ing infusion of artificial CSF, rats were resting or moving normally in the perfusion bowl.

When NMDA (125-250 $\mu \mathrm{M} ; 20 \mathrm{~min})$ was infused, mild behavioral excitation was observed, which included exploration of the cage, sniffing, and sporadic "wet-dog" shakes. During 20 min perfusion with $500 \mu \mathrm{M}$ NMDA some rats (about 1 of 3 ) displayed a "wild running" behavior consisting in rapid running around the cage with frequent collisions with the walls. This "wild running" behavior had no apparent influence on the cGMP response. Higher concentration of NMDA perfused through the probe for 20 min produced marked seizures (head nodding, forelimb clonus, falling on side and rolling). For this reason concentrations of NMDA higher than $500 \mu \mathrm{M}$ were not used. When the NMDA receptor antagonist D-AP5 was perfused for $40 \mathrm{~min}$ through the probe at the concentration of $500 \mu \mathrm{M}$, the behavior of the animals was unaffected. D-AP5 was able to prevent completely the behavioral activation induced by NMDA $(500 \mu \mathrm{M})$. No episodes of "wild running" were observed during the administration of $500 \mu \mathrm{M}$ NMDA in presence of D-AP5.

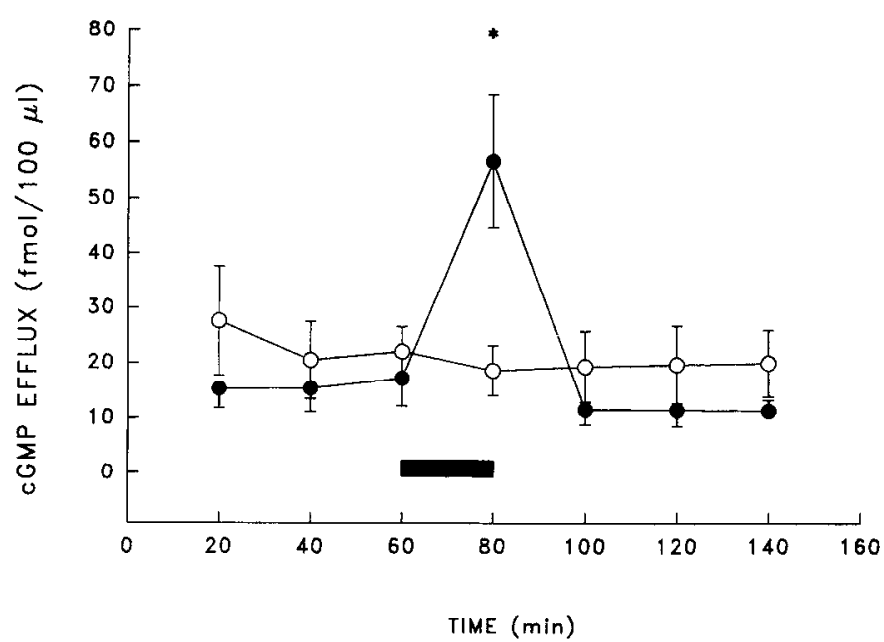

Figure 3. Effect of NMDA on basal extracellular levels of cGMP in rat hippocampus of freely moving rats. $\operatorname{NMDA}(500 \mu \mathrm{M})$ was perfused through the dialysis probe for $20 \mathrm{~min}$ as indicated by the horizontal bar. For other details, see Materials and Methods. Values are expressed as fmol $/ 100 \mu \mathrm{l}( \pm \mathrm{SEM} ; n=4-6$ for each group; data not corrected for in vitro recovery). $O$, controls; $\bullet, N M D A(500 \mu \mathrm{M}) .{ }^{*}, P<0.01$ versus controls and basal samples.

SNAP and hydroxylamine, at the concentration of $1 \mathrm{~mm}$, did not produce any obvious change of the animal behavior. In particular, no seizures were observed by perfusing the NO donors at the concentration used in our experiments $(1 \mathrm{~mm})$. Only at $10 \mathrm{~mm}$ did hydroxylamine produce a mild behavioral activation consisting in sporadic "wet-dog" shakes, sniffing, rearing, and digging in the sawdust.

IBMX, infused locally at $1 \mathrm{~mm}$ throughout the experiment, did not modify the behavior of the rats. Similarly, the NO synthase inhibitor NARG $(1-1000 \mu \mathrm{M})$ did not influence on its own the resting behavior of the animals, nor did it modify the behavioral activation induced by $500 \mu \mathrm{M}$ NMDA. L-Arginine ( $1 \mathrm{~mm}$ ) showed no significative alterations of the normal behavior of the rats.

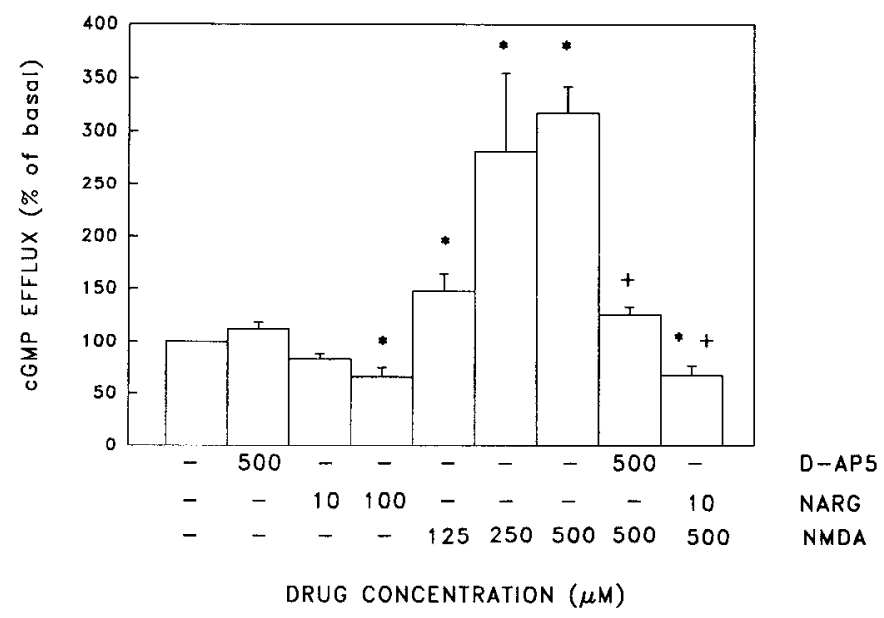

Figure 4. Effects of NMDA, NARG, and D-AP5 on the extracellular levels of cGMP in the hippocampus of freely moving rats. D-AP5 (500 $\mu \mathrm{M})$ and NARG (10 or $100 \mu \mathrm{M})$ were infused for $60 \mathrm{~min}$ prior co-infusion $(20 \mathrm{~min})$ with NMDA $(500 \mu \mathrm{M})$. Maximum responses are shown. The values are expressed as percentage of basal $( \pm \mathrm{SEM} ; n=4-6){ }^{*}, P<$ 0.01 versus controls and basal samples.,$+ P<0.01$ versus $500 \mu \mathrm{M}$ NMDA. 


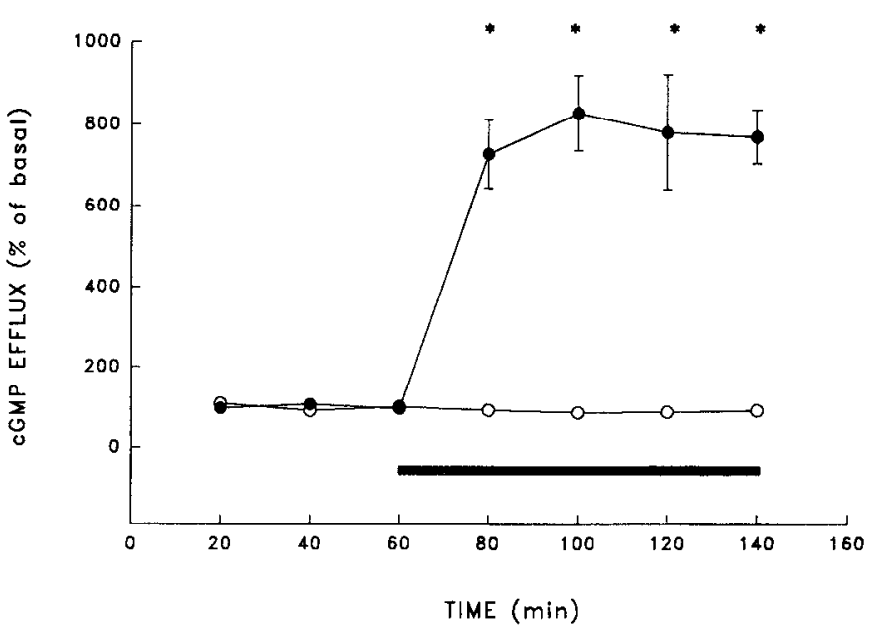

Figure 5. Effect of IBMX on basal extracellular levels of cGMP in rat hippocampus of freely moving rats. IBMX $(1 \mathrm{~mm})$ was perfused through the dialysis probe for $80 \mathrm{~min}$ as indicated by the horizontal bar. For other details, see Materials and Methods. Values are expressed as percentage of basal ( \pm SEM; $n=4-6$ for each group). Basal absolute values of CGMP $(22.1 \pm 3.7 \mathrm{fmol} / 100 \mu 1)$ did not differ significantly between the two sets of experiments and were grouped together. $O$, controls; $\boldsymbol{\theta}$, IBMX $(1 \mathrm{mM}){ }^{*}, P<0.01$ versus controls and basal samples.

\section{Discussion}

Methodological aspects. According to recent reports, the levels of extracellular cAMP measured during in vivo intracerebral microdialysis appear to reflect activation of adenylate cyclase mediated by brain aminergic receptors (Stone and John, 1990; Sijbesma et al., 1991).

In 1986, Tjörnhammar et al. found that a portion (10-15\%) of the cGMP, produced intracellularly when cerebellar slices were depolarized with high $\mathrm{K}^{+}$or were exposed to glutamic acid, appeared in the extracellular space. The efflux of cGMP into the medium seemed to reflect the increase in the intracellular nucleotide. Moreover, the extracellular levels could be lowered by probenecid, a known blocker of anion transport in membranes, suggesting the existence of a carrier-mediated efflux for cGMP.

The pivotal role that NO seems to play as an intercellular messenger in the brain, particularly in the hippocampus where it has been proposed to be involved in various processes including LTP (O'Dell et al., 1991; Schuman and Madison, 1991), prompted us to investigate the possibility of monitoring, during in vivo hippocampal microdialysis, the extracellular levels of cGMP and to ascertain whether and to what extent the nucleotide present in the dialysates could reflect the activity of NO synthase, the enzyme that catalyzes the production of NO, a major activator of guanylyl cyclase.

In order to investigate the relations between extracellular cGMP in hippocampus dialysates obtained from freely moving rats and the activity of NO synthase, a number of pharmacological manipulations expected to affect the NO synthase $\rightarrow$ NO $\rightarrow$ guanylyl cyclase $\rightarrow$ cGMP pathway were applied.

NO synthase inhibition. A number of drugs have been used as selective inhibitors of the cGMP-linked NO synthase. One of the most effective, NARG, was employed in our experiments. As shown in Figure 1, NARG concentration-dependently inhibited the cGMP levels present in the dialysates under basal conditions. The inhibition by NARG was counteracted by the NO synthase substrate L-arginine (data not shown, but see Fig.

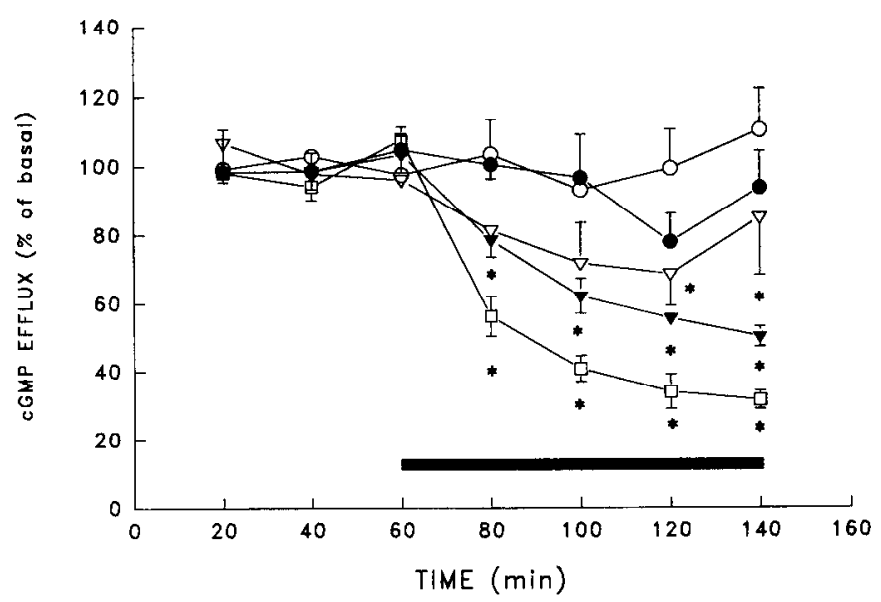

Figure 6. Effects of the NO synthase inhibitor NARG on extracellular levels of CGMP in the hippocampus of freely moving rats during IBMX perfusion. IBMX (1 mM) was perfused all throughout the experiment. The cGMP levels of the three $20 \mathrm{~min}$ fractions collected during IBMX perfusion but prior the administration of NARG were averaged and considered as "basal." Values are expressed as percentage of "basal" ( \pm SEM; $n=4-6$ for each group). The horizontal bar indicates the lime during which different concentrations of NARG were perfused through the probe. "Basal" absolute values of cGMP $(158.9 \pm 13 \mathrm{fmol} / 100 \mu \mathrm{l})$ did not differ significantly among the five sets of experiments and were grouped together. $O$, controls; - NARG $(1 \mu \mathrm{M}) ; \nabla$, NARG $(10 \mu \mathrm{M}) ; \boldsymbol{\nabla}$, NARG $(100 \mu \mathrm{M}) ; \square$, NARG $(1 \mathrm{~mm}) . *, P<0.01$ versus controls and "basal" samples.

7), a finding consistent with the idea that NARG acts as a competitive inhibitor of the enzyme.

High concentrations of NARG ( $1 \mathrm{~mm}$ ) were unable to abolish completely the basal outflow of cGMP, suggesting that a portion of the nucleotide recovered originates independently of an NARG-sensitive NO synthase. It should be noted that the brain NO synthase is $\mathrm{Ca}^{2+}$ dependent and that the basal outflow of cGMP was only in part sensitive to $\mathrm{Ca}^{2+}$ ions. The NARGinsensitive portion of cGMP could be generated by NO produced by NO synthase isoforms (Lambert et al., 1991; Moncada

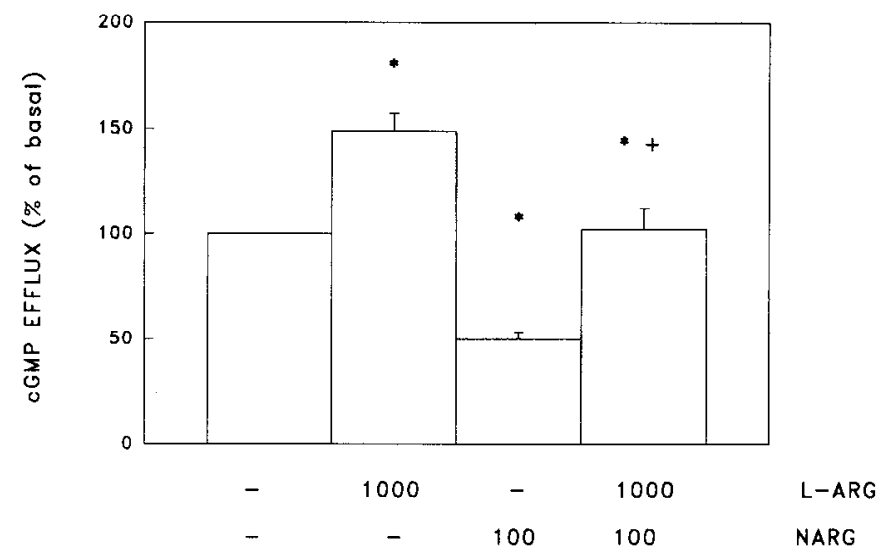

DRUG CONCENTRATION $(\mu \mathrm{M})$

Figure 7. Effect of L-arginine on the NARG-induced decrease of the extracellular levels of cGMP in the hippocampus of freely moving rats. IBMX (1 mM) was perfused all throughout the experiment. L-Arginine was administered for $60 \mathrm{~min}$ prior to co-infusion $(80 \mathrm{~min}$ ) with NARG $(100 \mu \mathrm{M})$. Maximum responses are shown. The values are expressed as percentage of basal ( \pm SEM; $n=4-6) .{ }^{*}, P<0.01$ versus controls and basal samples.,$+ P<0.01$ versus $100 \mu \mathrm{M}$ NARG. 
and IIiggs, 1991) or by other endogenous agents such as the atrial natriuretic factor (Waldman et al., 1984) or arachidonic acid (Snyder et al., 1984) acting on particulate or soluble guanylyl cyclase, respectively. Moreover, it was recently reported that activation of guanylyl cyclase and cGMP formation could be due to carbon monoxide originated under the catalysis of heme oxygenase-2 (Verma et al., 1993).

The present results demonstrate $\mathrm{NO}$ as the main intermediate prior to CGMP generation in the hippocampus of the waking rat. Very recently, Valtschanoff et al. (1993) studied the distribution and the electron microscopic morphology of NO synthase in rat hippocampus. The enzyme was found to be clearly expressed in a small fraction of neurons, most of which appear to be interneurons. The NO synthase-positive neurons were particularly concentrated in the pyramidal layer of the subiculum, in the subgranular zone of the dentate gyrus, and in the pyramidal layer of CA3, although cells in the pyramidal layer of CAl and CA2 were also stained.

NO donors. A number of compounds, including some clinically used nitrovasodilators, are able to generate $\mathrm{NO}$ and are now commonly used as donors of NO to tissues and cells. We chose hydroxylamine and SNAP, two drugs reported to raise cGMP levels in rat cerebellar slices (Southam and Garthwaite, 1991). These drugs ofler NO by two different mechanisms: catalase and probably other metalloproteins containing heme or flavin moieties present on the target cells are involved in the conversion of hydroxylamine to NO (Waldman and Murad, 1987), while SNAP can spontaneously generate NO by hydrolysis. The hydroxylamine-induced cGMP response displays tissue specificity possibly due to differences in the distribution of the catalyzing enzymes (Waldman and Murad, 1987). The finding that in rat hippocampus hydroxylamine produced a sustained increase in the extracellular levels of cGMP suggests that in this area the drug can easily be transformed into NO. The similar effect produced by SNAP guarantees that the cGMP response caused by hydroxylamine is due to NO produced in the hippocampal tissue.

The results obtained with the two generators of NO clearly show that reverse microdialysis represents an appropriate way to supply NO to selected areas of the brain or to peripheral tissues in order to activate guanylyl cyclase. The increase of cGMP reflects the expected activation of guanylyl cyclase by the NO directly produced from SNAP hydrolysis or metabolically originated from hydroxylamine.

Effects of NMDA receptor activation on the NO/CGMP pathway. Activation of NMDA receptors is known to raise cytosolic $\mathrm{Ca}^{2+}$, due largely to influx through the receptor-operated ion channel (Mayer and Miller, 1990). In the CNS this $\mathrm{Ca}^{2+}$ influx has been shown to stimulate NO synthase (Garthwaite et al., 1988; Knowles et al., 1989). One of the main actions of NO is to activate the soluble form of guanylate cyclase and so increase the levels of cGMP in target cells.

This chain of reactions has been particularly studied in the cerebellum (Bredt and Snyder, 1989; Garthwaite et al., 1989; Wood et al., 1990; Raiteri et al., 1991; Wood, 1991). Actually the in vitro or ex vivo measurement of cerebellar cGMP levels has been exploited as a functional response linked to NMDA receptor activation.

Preliminary results with adult rat hippocampal slices (East and Garthwaite, 1991) reported a cGMP response linked to NMDA receptor activation, which was however very weak as compared to that in cerebellum. Such a limited cGMP response must have hampered studies of the NO/cGMP system in the adult hippocampus. Indeed, only one recent report shows a consistent increase of the cGMP levels in the hippocampus of adult rats killed by microwave irradiation following intrahippocampal injection of NMDA (Wood et al., 1992). Therefore, the findings that the extracellular basal levels of cGMP together with their drug-induced up- and downmodulations could be easily monitored in the dialysate hippocampus of adult rats have been quite surprising.

Infusions of NMDA caused dose-related elevations of cGMP extracellular levels (Figs. 3, 4). Accordingly, the cGMP response was sensitive to the selective NMDA receptor recognition site antagonist D-AP5. Moreover, the raise of cGMP caused by 500 $\mu \mathrm{M}$ NMDA was totally abolished by $10 \mu \mathrm{M}$ NARG, clearly showing that, in the hippocampus of the living adult rat, activation of NMDA receptors is linked to NO production and synthesis of cGMP.

The basal outflow of cGMP was not diminished by D-AP5 (Fig. 4) or by the NMDA channel antagonist MK-801 (not shown), suggesting the absence of a tonic NMDA receptor activation. In other words, there can be little activation of NMDA receptors by spontaneously released excitatory amino acids, possibly due to the presence of $\mathrm{Mg}^{2+}$ ions blocking the receptor channel in the resting membrane.

Effects of phosphodiesterase inhibition. It has long been known that the hippocampus possesses a very efficient mechanism to regulate cGMP levels, since in this area the phosphodiesterase activity is about 10-fold higher than in cerebellum (Greenberg et al., 1978). Accordingly, the continuous perfusion through the dialysis probe of the phosphodiesterase inhibitor IBMX (1 mM) produced a pronounced (eightfold) raise of cGMP extracellular levels. The result suggests that, under basal conditions, the nucleotide is produced in large excess that is almost totally split by phosphodiesterase, although a portion escapes the hydrolysis and can be found in the extracellular fluid. The functional significance of such an efficient removal of cGMP remains to be established. The observation that the IBMX-induced elevation of cGMP remained stable over time does not seem to favor the presence of sensitive negative feedback mechanisms. The idea seems to be strengthened by the ability of the NO synthase substrate $\mathrm{L}$-arginine to increase cGMP formation even during IBMX infusion (Fig. 7). This finding also suggests that in the hippocampus of freely moving rats the endogenous level of L-arginine is not saturating for NO synthase.

It was observed that the levels of cGMP increased before the onset of drug-induced convulsions (Mao et al., 1974; Wood et al., 1982; McCaslin and Morgan, 1986). Moreover, stable cGMP derivatives were found to induce epileptic activity in pyramidal neurons (Hoffer et al., 1977). A role for cGMP in the genesis of epileptogenic activity has recently been proposed (De Sarro et al., 1993). However, during $3 \mathrm{hr}$ of intrahippocampal infusion with $1 \mathrm{mM}$ IBMX, no significative changes in the behavior of the animals were observed, in spite of the large cGMP response. Infusion with the NO donors hydroxylamine or SNAP, which potently increased CGMP formation, could not induce epileptic activity either. Seizures were instead clearly observed during NMDA administration at concentrations producing cGMP responses much lower than that seen with IBMX. Moreover, the seizures were abolished by the NMDA receptor antagonist D-AP5 but not by NARG, which prevented the cGMP response. Our results suggest that epileptogenic activity seems not to be directly related to cGMP levels in hippocampus. 
In a recent review the therapeutic potential of inhibitors of cyclic nucleotide phosphodiesterase in some central disorders, including depression, has been presented (Nicholson et al., 1991). The experimental setup employed in the present work may represent a useful model to evaluate in vivo novel drugs acting on cGMP phosphodiesterases.

Conclusions. The nucleotide cGMP released in the extracellular space of the adult rat hippocampus can be continuously monitored for long time intervals during microdialysis in the freely moving animal. Although the nucleotide is likely to originate from different pathways, NO synthase and its gaseous product appear of primary importance. Accordingly, the cGMP response can be drastically modulated by drugs related to $\mathrm{NO}$ synthase activity, leading to the conclusion that the extracellular levels of cGMP reflect the activity of this enzyme and its modulations in the hippocampus of living animals. Monitoring of cGMP during intracerebral microdialysis offers an interesting model for studying in vivo and during long time intervals the NMDA receptor complex and related drugs, activators, and inhibitors of NO synthase, NO donors and scavengers, as well as drugs acting at the nucleotide phosphodiesterases.

\section{References}

Bliss TVP, Collingridge GL (1993) A synaptic model of memory: longterm potentiation in the hippocampus. Nature 361:31-39.

Bredt DS, Snyder SH (1989) Nitric oxide mediates glutamate-linked enhancement of cGMP levels in the cerebellum. Proc Natl Acad Sci USA 86:9030-9033.

Bredt DS, Snyder SH (1990) Isolation of nitric oxide synthetase, a calmodulin-requiring enzyme. Proc Natl Acad Sci USA 87:682-685.

De Sarro G, Donato Di Paola E, De Sarro A, Vidal MJ (1993) LArginine potentiates excitatory amino acid-induced seizures elicited in the deep prepiriform cortex. Eur J Pharmacol 230:151-158.

East SJ, Garthwaite J (1991) NMDA receptor activation in rat hippocampus induces cyclic GMP formation through the L-argininenitric oxide pathway. Neurosci Letl 123:17-19.

Garthwaite J (1991) Glutamate, nitric oxide and cell-cell signalling in the nervous system. Trends Neurosci 14:60-67.

Garthwaite J, Charles SL, Chess-Williams K (1988) Endotheliumderived relaxing factor release on activation of NMDA receptors suggests role as intracellular messenger in the brain. Nature 336:385388.

Garthwaite J, Garthwaite G, Palmer RMJ, Moncada S (1989) NMDA receptor activation induces nitric oxide synthesis from arginine in rat brain slices. Eur J Pharmacol 172:413-416.

Greenberg LH, Troger E, Ferrendelli JA, Weiss B (1978) Enzymatic regulation of the concentration of cyclic GMP in mouse brain. Neuropharmacology 17:737-745.

Hoffer BJ, Seiger A, Taylor D, Olson L, Freeman R (1977) Seizures and related epileptiform activity in hippocampus transplanted to the anterior chamber of the eye. I. Characterization of seizures, interictal spikes and synchronous activity. Exp Neurol 54:233-239.

Ito M (1989) Long-term depression. Annu Rev Neurosci 12:85-102.

Knowles RG, Palacios M, Palmer RMJ, Moncada S (1989) Formation of nitric oxide from L-arginine in the central nervous system: a transduction mechanism for stimulation of the soluble guanylate cyclase. Proc Natl Acad Sci USA 86:5159-5162.

Lambert LE, Whitten IP, Baron BM, Cheng HC, Doherty NS, McDonald IA (1991) Nitric oxide synthesis in the CNS, endothelium and macrophages differs in its sensitivity to inhibition by arginine analogues. Life Sci 48:69-75.

Mao CC, Guidotti A, Costa E (1974) The regulation of cyclic guanosine monophosphate in rat cerebellum: possible involvement of putative amino acid neurotransmitters. Brain Res 79:510-514.

Mayer ML, Miller RJ (1990) Excitatory amino acid receptors, second messengers and regulation of intracellular $\mathrm{Ca}^{2+}$ in mammalian neurons. Trends Pharmacol Sci 11:254-260.

McCaslin PP, Morgan WW (1986) Continuously infused 2-amino-7phosphonoheptanoic acid antagonizes $N$-methyl-D-aspartate-induced elevations of cyclic GMP in vivo in multiple brain areas and chemically-induced seizure activity. Neuropharmacology 25:905-909.
Moncada S, Higgs EA (1991) Endogenous nitric oxide: physiology, pathology and clinical relevance. Eur J Clin Invest 21:361-374.

Moncada S, Palmer RMJ, Higgs EA (1989) Biosynthesis of nitric oxide from $\mathrm{L}$-arginine. A pathway for the regulation of cell function and communication. Biochem Pharmacol 38:1709-1715.

Nicholson CD, Challiss RAJ, Shahid M (1991) Differential modulation of tissue function and therapeutic potential of selective inhibitors of cyclic nucleotide phosphodiesterase isoenzymes. Trends Pharmacol Sci 12:19-27.

O'Dell TJ, Hawkins RD, Kandel ER, Arancia O (1991) Tests of the roles of two diffusible substances in LTP: evidence for nitric oxide as a possible early retrograde messenger. Proc Natl Acad Sci USA 88:11285-11289.

Paxinos G, Watson C (1986) The rat brain in stereotaxic coordinates. San Diego, CA: Academic.

Raiteri M, Maura G, Barzizza A (1991) Activation of presynaptic 5-hydroxytryptamine -like receptors on glutamatergic terminals inhibits $N$-methyl-D-aspartate-induced cyclic GMP production in rat cerebellar slices. J Pharmacol Exp Ther 257:1184-1188

Schuman EM, Madison DV (1991) A requirement for the intercellular messenger nitric oxide in long-term potentiation. Science 254:15031506 .

Shibuki K, Okada D (1991) Endogenous nitric oxide release required for long-term synaptic depression in the cerebellum. Nature 349:326328

Sijbesma H, Schipper J, Molewijk HE, Bosch AI, De Kloet ER (1991) 8-Hydroxy-2-(di- $n$-propylamino) tetralin increases the activity of adenylate cyclase in the hippocampus of freely-moving rats. Neuropharmacology 30:967-975.

Snyder RM, McKinney M, Forray C, Richelson E (1984) Neurotransmitter receptors mediate cyclic GMP formation by involvement of arachidonic acid and lipoxygenase. Proc Natl Acad Sci USA 81:39053909.

Snyder SH, Bredt DS (1991) Nitric oxide as a neuronal messenger. Trends Pharmacol Sci 12:125-128.

Southam E, Garthwaite J (1991) comparative effects of some nitric oxide donors on cyclic GMP levels in rat cerebellar slices. Neurosci Lett 130:107-111.

Southam E, East SJ, Garthwaite J (1991) Excitatory amino acid receptors coupled to the nitric oxide/cyclic GMP pathway in rat cerebellum during development. J Neurochem 56:2072-2081.

Stone EA, John SM (1990) In vivo measurement of extracellular cyclic AMP in the brain: use in studies of $\beta$-adrenoceptor function in nonanesthetized rats. J Neurochem 55:1942-1949.

Tjörnhammar M-L, Lazaridis G, Bartfai T (1986) Efflux of cyclic guanosine $3^{\prime}, 5^{\prime}$-monophosphate from cerebellar slices stimulated by L-glutamate or high $\mathrm{K}^{+}$or $N$-methyl- $N^{\prime}$-nitro- $N$-nitrosoguanidine. Neurosci Lett 68:95-99.

Ungerstedt U (1984) Measurement of neurotransmitter release by intracranial dialysis. In: Measurement of neurotransmitter release in vivo (Marsden CA, ed), pp 81-105. Chichester: Wiley.

Valtschanoff JG, Weinberg RJ, Kharazia VN, Nakane M, Schmidt HHHW (1993) Neurons in rat hippocampus that synthesize nitric oxide. J Comp Neurol 331:111-121.

Verma A. Hirsch DJ, Glatt CE, Ronnett GV, Snyder SH (1993) Carbon monoxide: a putative neural messenger. Science 259:381-384.

Waldman SA, Murad F (1987) Cyclic GMP synthesis and function. Pharmacol Rev 39:163-196.

Waldman SA, Rapoport RM, Murad F (1984) Atrial natriuretic factor selectively activates particulate guanylate cyclase and elevates cyclic GMP in rat tissues. J Biol Chem 259:14332-14334.

Wood PL (1991) Pharmacology of the second messenger, cyclic guanosine $3^{\prime}, 5^{\prime}$-monophosphate, in the cerebellum. Pharmacol Rev 43 $1-25$

Wood PL, Richard JW, Pilapil C, Nair NPV (1982) Antagonists of excitatory amino acids and cyclic guanosine monophosphate in cerebellum. Neuropharmacology 21:1235-1238.

Wood PL, Emmett MR, Rao TS, Cler J, Mick S, Iyengar S (1990) Inhibition of nitric oxide synthase blocks $N$-methyl-D-aspartate-, quisqualate-, kainate-, harmaline-, and pentylenetetrazole-dependent increases in cerebellar cyclic GMP in vivo. J Neurochem 55:346-348.

Wood PL, Ryan R, Li M (1992) Excitatory amino acid signal transduction in the hippocampus: role of noradrenergic afferents and nitric oxide in cGMP increases in vivo. Life Sci 51:601-606. 